Extracorporeal photopheresis in the treatment of acute graft-versus-host disease : a single-center experience

\title{
Niittyvuopio, Riitta
}

2018-08

Niittyvuopio , R , Juvonen , E , Heiskanen , J , Lindstrom , V , Nihtinen , A , Sahlstedt , L \& Volin , L 2018 , ' Extracorporeal photopheresis in the treatment of acute graft-versus-host disease : a single-center experience ' , Transfusion , vol. 58 , no. 8 , pp. 1973-1979 . https://doi.org/10.1111/trf.14649

http://hdl.handle.net/10138/305621

https://doi.org/10.1111/trf.14649

unspecified

publishedVersion

Downloaded from Helda, University of Helsinki institutional repository.

This is an electronic reprint of the original article.

This reprint may differ from the original in pagination and typographic detail.

Please cite the original version. 


\title{
Extracorporeal photopheresis in the treatment of acute graft-versus-host disease: a single-center experience
}

\author{
Riitta Niittyvuopio, Eeva Juvonen, Jouni Heiskanen, Vesa Lindström, Anne Nihtinen, \\ Leila Sahlstedt, and Liisa Volin
}

BACKGROUND: Steroid-refractory acute graft-versushost disease (aGVHD) is a serious complication after hematopoietic stem cell transplantation. The long-term outcome of the patients is poor. Various immunosuppressive agents have been proposed as the second-line therapy but none of them has turned out more effective than the others. Extracorporeal photopheresis (ECP) is a treatment option that does not predispose the patients to severe side effects of the immunosuppressive drugs.

STUDY DESIGN AND METHODS: We analyzed the treatment results of ECP in 52 patients with steroidrefractory or steroid-dependent aGVHD. Eighty-one percent of the patients suffered from a severe, Grade III or IV, aGVHD. ECP was started alone as the second-line treatment in 23 patients and in combination with an immunosuppressive drug in 18 patients. Eleven patients received ECP as the third-line or later treatment. RESULTS: A total of $62 \%$ of the patients responded, with $48 \%$ achieving complete response. In the patients with complete or partial response, the probabilities of survival at 4 years were 54 and $17 \%$, respectively. The outcome of nonresponders was poor. The 1-year overall survivals of the patients with ECP as the second-line treatment either alone or in combination with an immunosuppressive drug or as the third-line treatment were 51,28 , and $18 \%$, respectively. In multivariate analysis, starting ECP no later than 10 days after the start of the first-line treatment correlated with a good response and a consequent survival benefit.

CONCLUSION: Extracorporeal photopheresis is an effective and well-tolerated treatment that should be considered as a second-line treatment for aGVHD.
1 cute graft-versus-host disease (aGVHD) is a potentially fatal complication of allogeneic hematopoietic stem cell transplantation (alloHSCT). The standard first-line treatment is a high-dose steroid, either methylprednisone or methylprednisolone (MP; $2-10 \mathrm{mg} / \mathrm{kg} /$ daily). ${ }^{1}$ In approximately $40 \%$ to $50 \%$ of the patients with aGVHD, the disorder is steroid refractory. In these patients, the overall survival (OS) is only $17 \%$ at 2 years. $^{2}$ Several treatments, such as mycophenolate mofetil, infliximab, antithymocyte globulin (ATG), pentostatin, alemtuzumab, and mesenchymal stem cells, have been introduced but none of them has proved more effective than the others. ${ }^{3,4}$ Treatment with several immunosuppressive drugs leads to a severe immunosuppression and increases the risk of fatal complications.

Extracorporeal photopheresis (ECP) is a treatment modality in which buffy coat cells are separated by centrifugation and sensitized with 8-methoxypsoralen. ${ }^{5}$ The cells are radiated with ultraviolet A light and returned to the patient's circulation. The mode of action of ECP is not

ABBREVIATIONS: aGVHD = acute graft-versus-host disease; alloHSCT $=$ allogeneic hematopoietic stem cell transplantation; ATG = antithymocyte globulin; cGVHD = chronic graft-versus-host disease; $\mathrm{CR}=$ complete response; $\mathrm{ECP}=$ extracorporeal photopheresis; $\mathrm{HR}(\mathrm{s})=$ hazard ratio(s); $\mathrm{MP}=$ methylprednisolone; ORR(s) = overall response rate(s); OS $=$ overall survival; $\mathrm{PR}=$ partial response.

From the Department of Hematology, Comprehensive Cancer Center, Helsinki University Hospital, Helsinki, Finland.

Address reprint requests to: Riitta Niittyvuopio, Department of Hematology, Helsinki University Hospital, Haartmaninkatu 4, PL 372, 00029 HUS, Helsinki, Finland; e-mail: riitta.niittyvuopio@ hus.fi.

Received for publication October 26, 2017; revision received March 5, 2018; and accepted March 9, 2018.

doi:10.1111/trf.14649

(C) $2018 \mathrm{AABB}$

TRANSFUSION 2018;58;1973-1979 
completely understood. It has been suggested that the sensitized cells undergo apoptosis and are phagocytized by antigen-presenting cells, leading to the inhibition of proinflammatory cytokines, increased production of anti-inflammatory cytokines, and induction of regulatory T cells. ${ }^{6,7}$ ECP modulates dendritic cells, alters cytokine profile, and normalizes CD4+/CD8+ lymphocyte populations. ${ }^{8-11}$ Gatza and coworkers ${ }^{12}$ showed in murine models that the transfer of cells treated with ECP reversed established GVHD by increasing the numbers of donor regulatory $\mathrm{T}$ cells and by reducing the number of donor effector lymphocytes.

The beneficial effects of ECP are well documented in chronic GVHD (cGVHD). ${ }^{13}$ ECP is, however, not available in all centers or available only for patients with cGVHD. ${ }^{1}$ The knowledge of the efficacy of ECP in aGVHD is increasing but the numbers of patients in most publications have remained small. Five large studies with 128, 72, 59, 57, and 50 patients have been published. ${ }^{14-18}$ Two of them have included only children. ${ }^{15,17}$ In this study, we present our single-center experience of ECP in severe aGVHD.

\section{MATERIALS AND METHODS}

\section{Patients}

During the years 2002 to 2015, a total of 63 adult patients with steroid-refractory or steroid-dependent aGVHD were treated with ECP in Helsinki University Hospital. The data of 52 patients with at least two ECP procedures was included in the present retrospective analysis. Eight patients with only one procedure and three patients with aGVHD after donor leukocyte infusion were excluded. Clinical and transplant data are shown in Table 1. Twentyone patients received an allograft from a sibling, 30 patients received an allograft from an unrelated donor, and one patient received 2 units of cord blood. Three sibling donors showed one HLA antigen mismatch (two A and one DPB1) while the other sibling donors were 10 of 10 matches. Twenty-eight allografts from an unrelated donor were at least 10 of 12 HLA matches and two were nine of 12 matches. Both cord blood units were five of six matches.

\section{ECP}

ECP procedures were performed with one of two photopheresis systems (UVAR XTS [299 procedures] or Cellex [74 procedures], both Therakos) according to the manufacturer's guidelines. Both devices are fully automated. One ECP procedure was regarded as a single treatment. Venous access was provided either by G17 needles installed into a cubital vein or by a two-lumen central venous catheter. Heparin in sterile solution of $0.9 \% \mathrm{NaCl}$ was used as an anticoagulant, given at a ratio of 10:1. Methoxalen (Uvadex, Therakos) was injected to the
TABLE 1. Clinical and transplant data of 52 patients treated with ECP due to aGVHD*

\begin{tabular}{|c|c|}
\hline Number of patients & 52 \\
\hline Age (years) & $50(21-68)$ \\
\hline Sex, male/female & $28 / 24$ \\
\hline \multicolumn{2}{|l|}{ Disease } \\
\hline AML & 11 \\
\hline ALL & 7 \\
\hline MDS & 7 \\
\hline $\mathrm{NHL}$ & 7 \\
\hline CML & 6 \\
\hline MM & 6 \\
\hline MF & 5 \\
\hline CLL & 2 \\
\hline T-PLL & 1 \\
\hline \multicolumn{2}{|l|}{ Donor } \\
\hline Related/unrelated/double cord blood & $21 / 30 / 1$ \\
\hline Female donor/male recipient & $12(43)$ \\
\hline \multicolumn{2}{|l|}{ Stem cell source } \\
\hline Peripheral blood & $41(79)$ \\
\hline Marrow & $10(19)$ \\
\hline Double cord blood & $1(2)$ \\
\hline \multicolumn{2}{|l|}{ ABO blood group difference } \\
\hline $\begin{array}{l}\text { Identical/minor incompatibility/ } \\
\text { major incompatibility }\end{array}$ & $30 / 11 / 11$ \\
\hline \multicolumn{2}{|l|}{ Conditioning } \\
\hline $\begin{array}{l}\text { Myeloablative (18 CyTBI, } 7 \text { BuCy, } \\
14 \text { treosulfan } 42 \mathrm{~g} / \mathrm{m}^{2} \text { ) }\end{array}$ & $39(75)$ \\
\hline Reduced-intensity conditioning & $13(25)$ \\
\hline \multicolumn{2}{|l|}{ GVHD prophylaxis } \\
\hline CsA plus Mtx & $35(67)$ \\
\hline CsA plus Mtx plus MP & $9(17)$ \\
\hline CsA plus mycophenolate mofetil & $8(15)$ \\
\hline Pretransplant ATG & $22(42)$ \\
\hline \multicolumn{2}{|l|}{ Acute GVHD } \\
\hline Grade I & $3(6)$ \\
\hline Grade II & 7 (14) \\
\hline Grade III & $34(65)$ \\
\hline Grade IV & $8(15)$ \\
\hline One-organ involvement & $30(58)$ \\
\hline Two-organ involvement & $21(40)$ \\
\hline Three-organ involvement & $1(2)$ \\
\hline \multicolumn{2}{|c|}{$\begin{array}{l}\text { * Data are reported as number, median (range), or number (\%). } \\
\mathrm{AML}=\text { acute myeloid leukemia; } \mathrm{ALL}=\text { acute lymphoblastic } \\
\text { leukemia; } \mathrm{Bu}=\text { busulfan; } \mathrm{CLL}=\text { chronic lymphocytic leukemia; } \\
\mathrm{CML}=\text { chronic myeloid leukemia; } \mathrm{Cs}=\text { cyclosporine } \mathrm{A} \text {; } \\
\mathrm{Cy}=\text { cyclophosphamide; } \mathrm{MF}=\text { myelofibrosis; } \mathrm{MDS}=\text { myelodys- } \\
\text { plastic syndrome; } \mathrm{MM}=\text { multiple myeloma; } \mathrm{Mtx}=\text { methotrexate; } \\
\mathrm{NHL}=\text { non-Hodgkin lymphoma; } \mathrm{TBI}=\text { total body irradiation; } \\
\mathrm{T}-\mathrm{PLL}=\mathrm{T} \text {-prolymphocytic lymphoma. }\end{array}$} \\
\hline
\end{tabular}

collection bag in a dose of $0.017 \mathrm{~mL}$ per $1 \mathrm{~mL}$ of the apheresis product before photoactivation.

Before each ECP, the hemodynamic status of the patient had to be stable and a white blood cell count of at least $1 \times 10^{9} / \mathrm{L}$. If necessary, the patients were transfused with red blood cells or platelets (PLTs) to maintain a hematocrit level of at least $25 \%$ and a PLT count of at least $40 \times 10^{9} / \mathrm{L}$.

ECP procedures were performed twice a week, but not on consecutive days, with the exception of the first patient, who was treated on consecutive days. ECPs were continued twice a week until the maximum response. Maintenance ECPs were not given. 


\section{Definitions of aGVHD and evaluation criteria of response}

aGVHD was classified as Grade I to IV according to the Glucksberg-Seattle scoring system. ${ }^{19}$ Steroid-refractory aGVHD was defined as a progression of symptoms within 3 days of the start of the high-dose steroid, no improvement of symptoms despite the treatment with steroids at a dose of at least $2 \mathrm{mg} / \mathrm{kg}$ for 7 days, or incomplete response after 14 days of 1 to $2 \mathrm{mg} / \mathrm{kg} /$ day corticosteroid therapy. ${ }^{20}$ Patients who experienced a flare of symptoms during a steroid taper were regarded as steroiddependent. $^{21}$

Resolution of all aGVHD symptoms in all involved organs was defined as a complete response (CR) and a significant improvement of symptoms as a partial response (PR). ${ }^{22}$ No response referred to a stable organ involvement or a progression of aGVHD.

\section{Statistical analysis}

Overall survival was defined as the time from the ECP onset to the time of death from any cause. Survival between different response statuses (CR, PR, no response) was compared by using the Kaplan-Meier life-table method and an unstratified log-rank test ( $p$ values) and unstratified Cox proportional hazards model. The analyses related to prognostic factors (grade, timing of ECP, treatment line, numbers of involved organs) were performed similarly, with each prognostic factor analyzed at a time. Based on the results of the univariate modeling, a multivariate model was constructed, with the explanatory variables consisting of the prognostic factors that had been proven to be meaningful in the univariate analysis. Hazard ratios (HRs) and their 95\% confidence intervals (CIs) were used to quantify the results of the Cox models.

The effect of prognostic factors (grade, timing of ECP, treatment line, and number of involved organs) on response status was analyzed with univariate logistic regression applying Firth's bias adjustment method separately for each factor. Based on the results of the univariate modeling, a multivariate logistic regression analysis was constructed. Odds ratios (ORs) and their 95\% CIs were used to quantify the results of the logistic regression analysis. The ORs were constructed for the probability of reaching a response.

$\mathrm{p}$ values of less than 0.05 were considered significant, the $\mathrm{p}$ values are two-tailed and not adjusted for multiple testing. Comparisons of categorical variables between two cohorts were performed using the Fisher exact test. Statistical analyses were carried out with computer software (SAS for Windows, Version 9.3, SAS Institute). Patient data for Kaplan-Meier survival curves were analyzed with computer software (SPSS, Version 22, IBM Corp.).

\section{RESULTS}

\section{Characteristics of aGVHD}

Forty-two patients (81\%) had a steroid-refractory and 10 patients (19\%) a steroid-dependent aGVHD. aGVHD appeared at a median of 41 days (range, 10-332 days) after the alloHSCT. Seven patients (13\%) were diagnosed as having aGVHD after Day +100. In two of them, the late aGVHD appeared upon immunosuppression withdrawal on Days +245 and +332 .

Three patients $(6 \%)$ had Grade I, seven patients (14\%) Grade II, 34 patients (65\%) Grade III, and eight patients (15\%) Grade IV aGVHD (Table 1). Neither the source of the graft nor the conditioning regimen had significant impact on the risk of severe aGVHD. Seven of $10(70 \%)$ patients transplanted with a marrow graft and 35 of 41 (85\%) patients transplanted with blood stem cells showed Grade III or IV aGVHD. Of the patients treated with myeloablative or reduced-intensity conditioning, 85 and $77 \%$ presented with Grade III or IV aGVHD, respectively.

At the start of ECP, 30 patients showed one-organ involvement (20 gut, 10 skin), 21 patients two-organ involvement (19 skin plus gut, one gut plus liver, one skin plus liver), and one patient had three-organ involvement (skin plus gut plus liver). The diagnosis of aGVHD of the skin was based on clinical evaluation. All gut disorders were confirmed histologically, whereas the diagnosis of aGVHD of the liver was based on laboratory tests. All patients received MP at a dose of $2 \mathrm{mg} / \mathrm{kg}$ or more as the first-line treatment. Cyclosporine A was continued in all patients.

\section{ECP in the treatment algorithm}

Forty-one patients (79\%) received ECP as the second-line treatment. Twenty-three of them were treated with ECP only, whereas in 18 patients ECP was started concomitantly with an immunosuppressive drug (10 with pentostatin and eight with infliksimab, ATG, or alemtuzumab). In 11 patients $(21 \%)$, ECP was the third-line or later treatment. The previous therapies consisted of pentostatin (six patients), infliximab (six patients), mycophenolate mofetil (two patients), ATG (one patient), or an infusion of mesenchymal stem cells (one patient).

Of the 23 patients treated with ECP alone as the second-line treatment, 10 patients $(43 \%)$ had Grade I or II and 13 patients (57\%) Grade III-IV aGVHD. All the other patients, that is, those treated with combination therapy as the second-line treatment or those receiving third-line treatment, presented with Grade III or IV aGVHD.

Extracorporeal photopheresis was started at the median of 11 days (range, 2-102 days) after the beginning of the high-dose MP or, in steroid-dependent patients, after the increase of the MP dose. In 15 patients, ECP was initiated within 7 days of the start of MP or the increase of its dose. In nine of them, the cause was a rapid progression of 


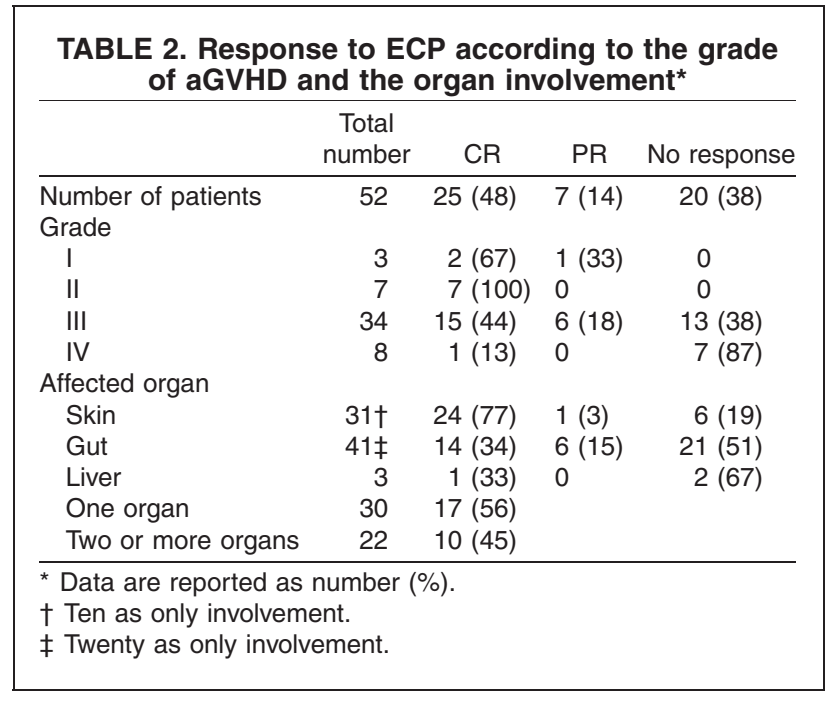

the symptoms and in the rest a rapid recurrence of the symptoms after a reduction in MP dose.

The median number of ECPs per patient was six (range, 2-21). ECPs were well tolerated. One patient experienced respiratory problems, resulting in the discontinuation of ECPs after the third treatment.

\section{Response of ECP in aGVHD}

Thirty-two of 52 patients $(62 \%)$ responded to the treatment while 20 patients (38\%) did not show any response (Table 2). The first signs of response could be seen after a median of three ECP procedures (range, two to eight). Twenty-five patients (48\%) achieved CR and seven patients (14\%) PR. The median daily steroid dose at the start of ECP was $2 \mathrm{mg} / \mathrm{kg}$ (range, $0.3-10 \mathrm{mg} / \mathrm{kg}$ ). In those patients with a CR or PR, the median dose of MP was reduced to $0.6 \mathrm{mg} / \mathrm{kg}$ at +30 days and to $0.4 \mathrm{mg} / \mathrm{kg}$ at +60 days from the start of ECP. Thirteen of 17 surviving patients have shown cGVHD during the follow-up. At the time of the present analysis, nine patients receive immunosuppressive treatment for cGVHD.

The grade of aGVHD predicted the probability of response to ECP (Table 2). Some response was seen in all 10 patients with Grade I or II, in 21 of 34 patients (62\%) with Grade III, and in one of eight patients (13\%) with Grade IV aGVHD. Most patients (eight of 10) with Grade I or II aGVHD showed CR. In Grades III and IV, CR was seen less frequently: in Grade III in 15 of 34 patients (44\%) and in Grade IV in one of eight patients (13\%; Fig. 1A).

The skin proved the most favorable target for ECP, with $77 \%$ of the patients showing CR. In gut and liver aGVHD, the CR rates were inferior, 34 and 33\%, respectively (Fig. 1B). The number of affected organs did not predict the probability of response. Fifty-six percent of the patients with one-organ involvement and $45 \%$ of those with at least two organs involved reached CR.
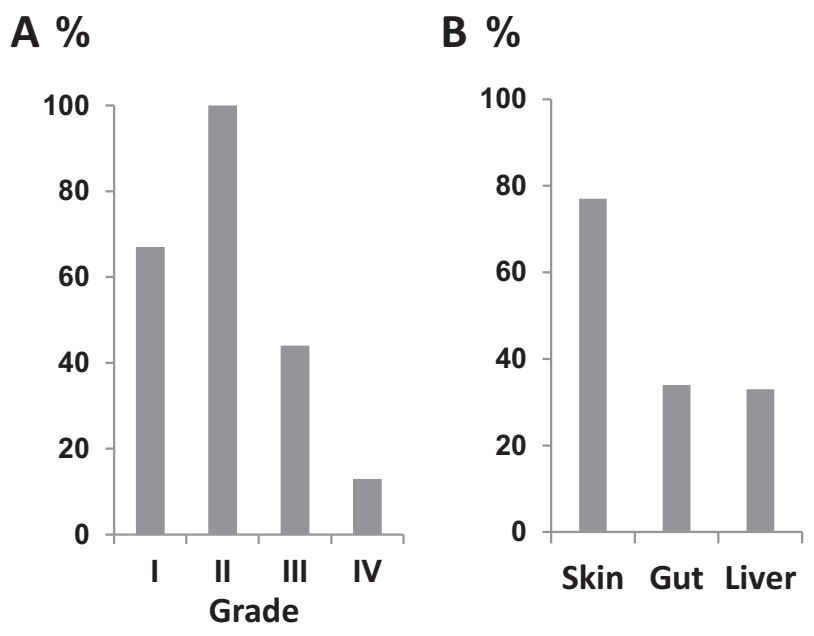

Fig. 1. (A) CR rates according to severity of aGVHD. (B) CR response rates according to organ involvement of aGVHD.

In univariate analysis, the probability of achieving response correlated with the earlier start of ECP (OR, 6.040; 95\% CI, 1.746-20.888; $\mathrm{p}<0.005)$ and the treatment line (OR, 10.523; 95\% CI, 1.982-55.859; $\mathrm{p}=0.02$ ). When ECP was started within 10 days of the start of the highdose steroid, 16 of 25 patients (64\%) obtained CR. Of the 27 patients with delayed start of ECP, only nine (33\%) achieved CR. In the patients suffering from Grade III or IV aGVHD, an early start of ECP resulted in CR in 12 patients (57\%) while in those with a delayed start, CR was seen in four patients $(19 \% ; \mathrm{p}=0.02)$. The majority of those who received ECP as the second-line treatment showed CR or PR (Table 3). The overall response rates (ORRs) with ECP alone in the second line was 83 and $56 \%$ for ECP combined with an immunosuppressive drug. In the third line, the ORR was $27 \%$.

In multivariate analysis, the only significant factor related to the response rate was the early start of ECP. The response rate was significantly better if ECP procedures were initiated within 10 days of the start of a high-dose steroid in steroid-refractory aGVHD or of an increase in MP in steroid-dependent aGVHD (OR, 5.274; 95\% CI, 1.212-22.943; $\mathrm{p}=0.03$ ). The grade of aGVHD had no significant impact on the response rate in multivariate analysis.

\section{Survival}

The median follow-up time for all patients was 6 months (range, 1-156 months) from the start of ECP. Seventeen patients (33\%) were alive after a median follow-up of 31 months (range, 5-156 months) from the ECP onset, while 35 patients had died at a median of 3 months (range, 1-25 months). Fifty-three percent of the patients (17/32) with any response to ECP were alive, while none of the 20 nonresponding patients survived. The cause of death in all 
TABLE 3. Response to ECP in 52 patients with aGVHD, the number of patients alive at the time of the present analyses, and the transplant-related mortality (TRM) according to the ECP groups*

\begin{tabular}{|c|c|c|c|c|c|c|c|}
\hline \multirow[b]{2}{*}{ ECP } & \multirow[b]{2}{*}{ Total number } & \multicolumn{3}{|c|}{ Response } & \multirow[b]{2}{*}{ No response } & \multirow[b]{2}{*}{ Alive } & \multirow[b]{2}{*}{ TRM } \\
\hline & & Any & $\mathrm{CR}$ & PR & & & \\
\hline Second-line & 41 & & & & & & \\
\hline Alone & 23 & 19 (83) & 16 & 3 & $4(17)$ & $10(43)$ & $11(48)$ \\
\hline In combination† & 18 & $10(56)$ & 7 & 3 & $8(44)$ & $5(28)$ & 12 (67) \\
\hline Third-line & 11 & $3(27)$ & 2 & 1 & $8(73)$ & $2(18)$ & $9(82)$ \\
\hline
\end{tabular}

* Data are reported as number (\%).

† Pentostatin, infliximab, ATG, or alemtuzumab.

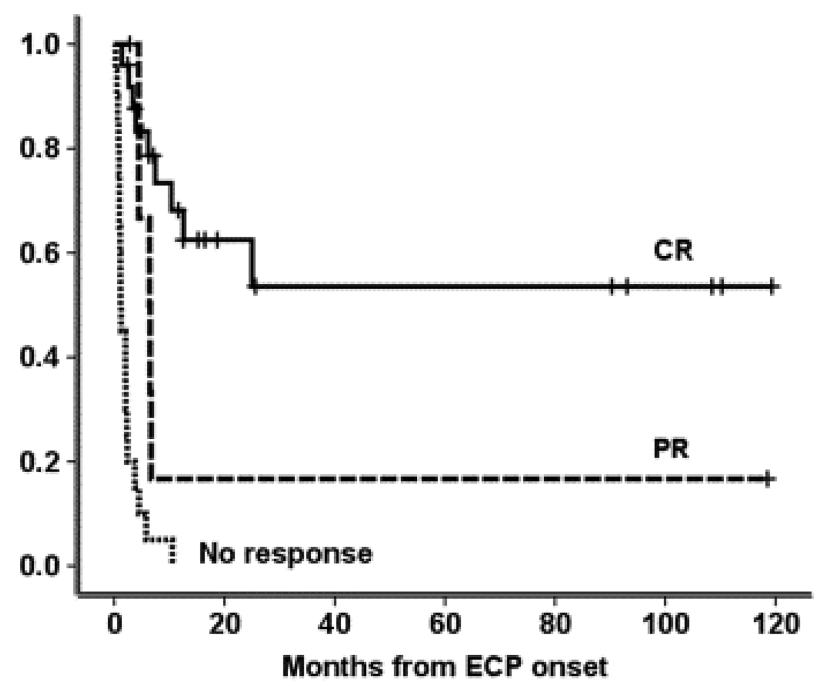

Fig. 2. Survival of patients treated with ECP according to the treatment response.

nonresponding patients was aGVHD. In addition, 15 of 32 responders died during a median follow-up of 9 months (range, 3-28 months), including five patients with PR and 10 with CR. The main cause of death was a transplantrelated complication: an infection, late recurrent aGVHD, or cGVHD. Two patients, both with CR, had a relapse of the hematologic malignancy.

In patients with $\mathrm{CR}$ or $\mathrm{PR}$, the probabilities of survival at 4 years from ECP onset were 54 and 17\%, respectively (Fig. 2). The outcome of the patients with no response was dismal. The 1-year survivals of the patients with ECP as the second-line treatment alone or in combination with an immunosuppressive drug or as the third-line treatment were 51, 28, and 18\%, respectively (Fig. 3). Accordingly, 1-year transplant-related mortalities were 43, 68 , and $82 \%$ in these groups.

In univariate analysis, the significant prognostic factors for survival were CR to ECP (HR, 0.08; 95\% CI, 0.03-0.19; $\mathrm{p}<0.0001)$ and the start of ECP within 10 days of the initiation of a high-dose MP (HR, 0.41; 95\% CI, 0.21-0.82; $\mathrm{p}=0.009$ ). The number of involved organs, grade, or ECP treatment line did not predict survival. In multivariate analysis, the start of ECP within 10 days was associated

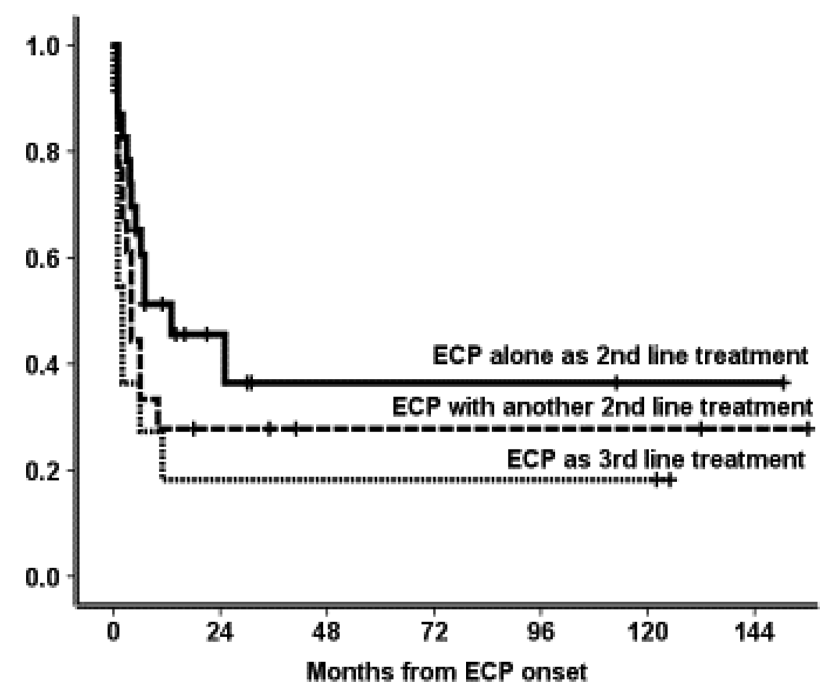

Fig. 3. Survival of patients treated with ECP as a second-line treatment, either alone or in combination with another immunosuppressive drug or as a third-line treatment.

with improved survival (HR, 0.42; 95\% CI, 0.20-0.90; $\mathrm{p}=0.009$ ).

\section{DISCUSSION}

The results of this analysis of ECP in the treatment of aGVHD are encouraging. More than half of the patients (36/52) responded. The prognosis of the patients who achieved CR was better than the prognosis of those with only PR or no response. The early start of ECP after the failure of steroid treatment was associated with a higher probability of a good response, also in patients with Grade III or IV aGVHD, translating to a survival benefit.

The CR rate in our study (48\%) was somewhat lower than that in some of the previous publications with adult patients $(52 \%-91 \%)^{14,18,23}$ but in line with some other reports, such as that by Perfetti and colleagues ${ }^{24}(52 \%)$ and Hautmann and colleagues ${ }^{21}(30 \%)$. A total of $62 \%$ of the present patients showed some response to ECP, and in the second-line treatment the ORR was $71 \%$, while the CR rate was $56 \%$. In the largest study with 128 adult patients with steroid-refractory or steroid-dependent aGVHD, ${ }^{14}$ 
the ORR of ECP as the second-line treatment was 77\% and the CR rate was $67 \%$. However, in the study by Das-Gupta and colleagues, ${ }^{14}$ the proportion of the patients with Grade III or IV aGVHD was lower than that in this study (30\% vs. $81 \%$, respectively). In our patient population, in line with previous reports, ${ }^{14,16,18,23,24}$ the skin involvement presented the most favorable target (CR, 77\%), whereas only one-third of our patients with gut or liver involvement showed CR. Greinix and colleagues ${ }^{16}$ have reported better results; up to two-thirds of their adult patients with liver or gut aGVHD achieved CR. The highest CR rates in gut involvement, up to $75 \%$, have been reported in children. ${ }^{15,17,25}$

The differences in response rates may be explained by differences in patient populations and local practices in transplant centers. In our study, the proportion of the patients with severe aGVHD was high, $81 \%$, compared with many of the other studies in which $20 \%$ to $60 \%$ of the patients suffered from Grade III or IV aGVHD. ${ }^{14,16,18,23,24}$ In the study by Malagola and colleagues, ${ }^{23}$ in which the ORR was as high as $91 \%$, the majority of the patients (80\%) presented with Grade II aGVHD. In addition, the proportion of the present patients with steroid-refractory aGVHD was higher $(81 \%)$ than that in the studies by Greinix and colleagues $^{16}$ (37\%) and Malagola and colleagues ${ }^{23}$ (49\%). Within our patient population, in one-fifth of the cases, ECP procedures were initiated in the third-line or later, while most studies have reported efficacy of ECP as a second-line treatment. Local practices in place at the transplant centers may also have an impact on the differences in the results. The majority of the reports are based on the experiences of a single center. Different centers may have different policies concerning indications, timing, and availability of ECP, thus leading to variable treatment results.

The prompt start of ECP may be the most crucial aspect of the treatment of severe aGVHD. In our patients, the start of ECP within 10 days of the beginning of the high-dose MP showed significant association with a response and a survival benefit. In addition, a significant proportion (57\%) of the seriously ill patients with Grade III or IV aGVHD also responded to the early start of ECPs. In the study of Perfetti and colleagues, ${ }^{24}$ the initiation of ECP within 35 days of the aGVHD diagnosis resulted in higher response rates. In several studies, the efficacy of ECP has been shown to be better in patients with a lower-grade aGVHD. ${ }^{14,16,17,24}$ Das-Gupta and colleagues $^{14}$ reported a better 2-year OS and a lower 2-year nonrelapse mortality in the patients with lower stages of liver involvement and lower aGVHD grades. Therefore, an early start of ECP should be considered before irreversible tissue changes manifest. The Italian expert groups (SIdEM and GITMO) have introduced to their guidelines a recommendation of an early start of ECP in the treatment of aGVHD. ${ }^{26}$

We know that our study has several limitations due to its retrospective nature and the long study period. At present, in many transplant centers, ECP is regarded as one of the second-line treatment options in steroidrefractory aGVHD even though its status is not fully established. ${ }^{1}$ Sixteen years ago, when the first of our patients was treated, ECP was a highly experimental treatment and mainly seen as a component of a combination therapy. In our center, the confidence in the benefits of ECP in severe aGVHD has increased during the study period, which has resulted in modifications in our practice. During 2002 to 2007 , for $75 \%$ of the patients, ECP was started in combination with an immunosuppressive drug, such as ATG, infliximab, alemtuzumab, or pentostatin. Since 2008, ECP has not been combined with immunosuppressive drugs except with pentostatin for the treatment of steroidrefractory gut aGVHD. Thus, over the past 10 years, approximately half of the ECPs in our clinic have been carried out as the only second-line treatment of aGVHD. The change in the treatment policy is a consequence of our encouraging results and thus it may have caused a bias in this study.

Acute GVHD is the most serious treatment-related complication occurring after alloHSCT. Approximately $30 \%$ to $50 \%$ of the patients with aGVHD need a second-line treatment. $^{27,28}$ The prognosis of patients with steroidrefractory Grade III or IV aGVHD is dismal, hampering prospective randomized studies of ECP. ${ }^{29}$ Approximately $80 \%$ of our patients belonged to the group with a poor prognosis. Various immunosuppressive agents have been proposed as the second-line therapy ${ }^{4,30}$ but especially the long-term survival of the patients with Grade III or IV aGVHD has improved only a little during the past decades. ${ }^{29,31}$ Several lines of immunosuppressive drugs expose patients to severe side effects such as fatal infections. Therefore, effective therapies that do not predispose patients to infections or other steroid-related complications (osteoporosis, diabetes, etc.) are highly desired. On the basis of our experiences, ECP is an effective and well-tolerated treatment option for patients also with severe aGVHD.

\section{CONFLICT OF INTEREST}

RN received financial support from Mallinckrodt Pharmaceuticals for collection and analysis of the patient data. The remaining authors have disclosed no conflicts of interest.

\section{REFERENCES}

1. Ruutu T, van Biezen A, Hertenstein B, et al. Prophylaxis and treatment of GVHD after allogeneic haematopoietic SCT: a survey of centre strategies by the European Group for Blood and Marrow Transplantation. Bone Marrow Transplant 2012; 47:1459-64.

2. Westin JR, Saliba RM, De Lima M, et al. Steroid-refractory acute GVHD: predictors and outcomes. Adv Hematol 2011; 2011:601953. 
3. Holtan SG, Pasquini M, Weisdorf D. Acute graft-versus-host disease: a bench-to-bedside update. Blood 2014;124:363-73.

4. Dignan FL, Clark A, Amrolia P, et al. Diagnosis and management of acute graft-versus-host disease. Br J Haematol 2012; 158:30-45.

5. Edelson R, Berger C, Gasparro F, et al. Treatment of cutaneous T-cell lymphoma by extracorporeal photochemotherapy. Preliminary results. N Engl J Med 1987;316:297-303.

6. Bladon J, Taylor P. Extracorporeal photopheresis normalizes some lymphocyte subsets (including $\mathrm{T}$ regulatory cells) in chronic graft-versus-host-disease. Ther Apher Dial 2008;12: 311-8.

7. Holtick U, Marshall SR, Wang X, et al. Impact of psoralen/ UVA-treatment on survival, activation, and immunostimulatory capacity of monocyte-derived dendritic cells. Transplantation 2008;85:757-66.

8. Berger C, Hoffman K, Vasquez JG, et al. Rapid generation of maturationally synchronized human dendritic cells; contribution to the clinical efficacy of extracorporeal photochemotherapy. Blood 2010;116:4838-47.

9. Voss CY, Fry TJ, Coppes MJ, et al. Extending the horizon for cell-based immunotherapy by understanding the mechanisms of action of photopheresis. Transfus Med Rev 2010;24:22-32.

10. Goussetis E, Varela I, Tsirigotis P. Update of the mechanism of action and on clinical efficacy of extracorporeal photopheresis in the treatment of acute and chronic graft versus host disease in children. Transfus Apher Sci 2012;46:203-9.

11. Edelson RL. Mechanistic insights into extracorporeal photochemotherapy: efficient induction of monocyte-to-dendritic cell maturation. Transfus Apher Sci 2014;50:322-9.

12. Gatza E, Rogers CE, Clouthier SG, et al. Extracorporeal photopheresis reverses experimental graft-versus-host disease through regulatory T cells. Blood 2008;112:1515-21.

13. Perotti C, Sniecinski I. A concise review on extracorporeal photochemotherapy: where we began and where we are now and where we are going!. Transfus Apher Sci 2015;52:360-8.

14. Das-Gupta E, Greinix H, Jacobs R, et al. Extracorporeal photopheresis as second-line treatment for acute graft-versushost disease: impact on six-month freedom from treatment failure. Haematologica 2014;99:1746-52.

15. Calore E, Marson P, Pillon M, et al. Treatment of acute graftversus-host disease in childhood with extracorporeal photochemotherapy/photopheresis: the Padova experience. Biol Blood Marrow Transplant 2015;21:1963-72.

16. Greinix HT, Knobler RM, Worel N, et al. The effect of intensified extracorporeal photochemotherapy on long-term survival in patients with severe acute graft-versus-host disease. Haematologica 2006;91:405-8.

17. Perotti C, Del Fante C, Tinelli C, et al. Extracorporeal photochemotherapy in graft-versus-host disease: a longitudinal study on factors influencing the response and survival in pediatric patients. Transfusion 2010;50:1359-69.

18. Jagasia M, Greinix H, Robin M, et al. Extracorporeal photopheresis versus anticytokine therapy as a second-line treatment for steroid-refractory acute GVHD: a multicenter comparative analysis. Biol Blood Marrow Transplant 2013; 19:1129-33.

19. Glucksberg H, Storb R, Fefer A, et al. Clinical manifestations of graft-versus-host disease in human recipients of marrow from HLA-matched sibling donors. Transplantation 1974;18: 295-304.

20. Pidal J, Anasetti C. Glucocorticoid-refractory acute graft-versushost disease. Biol Blood Marrow Transplant 2010;16:1504-18.

21. Hautmann AH, Wolff D, Hahn H, et al. Extracorporeal photopheresis in 62 patients with acute and chronic GVHD: results of treatment with COBE Spectra system. Bone Marrow Transplant 2013;48:439-45.

22. Greinix HT, Volc-Platzer B, Kalhs P, et al. Extracorporeal photochemotherapy in the treatment of severe steroid-refractory acute graft-versus-host disease: a pilot study. Blood 2000;96: 2426-31.

23. Malagola M, Cancelli V, Skert C, et al. Extracorporeal photopheresis for treatment of acute and chronic graft versus host disease: an Italian multicentric retrospective analysis on 94 patients on behalf of the Gruppo Italiano Trapianto di Midollo Osseo. Transplantation 2016;100:e147-55.

24. Perfetti P, Carlier P, Strada P, et al. Extracorporeal photopheresis for the treatment of steroid refractory acute GVHD. Bone Marrow Transplant 2008;42:609-17.

25. Messina C, Locatelli F, Lanino E, et al. Extracorporeal photochemotherapy for paediatric patients with graft-versus-host disease after haematopoietic stem cell transplantation. Br J Haematol 2003;122:118-27.

26. Pierelli L, Perseghin P, Marchetti M, et al. Extracorporeal photopheresis for the treatment of acute and chronic graftversus-host disease in adults and children: best practice recommendations from an Italian Society of Hemapheresis and Cell Manipulation (SIdEM) and Italian Group for Bone Marrow Transplantation (GITMO) consensus process. Transfusion 2013;53:2340-52.

27. Van Lint MT, Uderzo C, Locasciulli A, et al. Early treatment of acute graft-versus-host disease with high or low-dose 6methylprednisolone: a multicentre randomized trial from the Italian Group for Bone Marrow Transplantation. Blood 1998;92:2288-93.

28. MacMillan ML, Weisdorf DJ, Wagner JE, et al. Response of 443 patients to steroids as primary therapy for acute graftversus-host disease: comparison of grading systems. Biol Blood Marrow Transplant 2002;8:387-94.

29. Jamani K, Russell JA, Daly A, et al. Prognosis of grade 3-4 acute GVHD continues to be dismal. Bone Marrow Transplant 2013;48:1359-61.

30. Martin PJ, Rizzo JD, Wingard JR, et al. First- and second-line systemic treatment of acute graft-versus-host disease: recommendations of the American Society of Blood and Marrow Transplantation. Biol Blood Marrow Transplant 2012;18: 1150-63.

31. Schmitt T, Luft T, Hegenbart U, et al. Pentostatin for treatment of steroid-refractory acute GVHD: a retrospective singlecenter analysis. Bone Marrow Transplant 2011;46:580-5. 